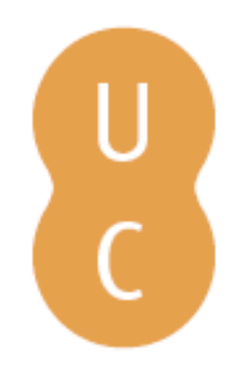

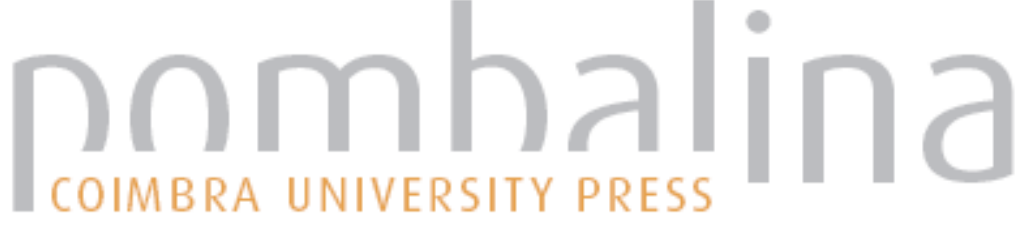

\section{Que fundamentos para uma educação em tempo de crise?}

\author{
Autor(es): Boavida, João \\ Publicado por: Imprensa da Universidade de Coimbra \\ URL \\ persistente: URI:http://hdl.handle.net/10316.2/32410 \\ DOI: $\quad$ DOI:http://dx.doi.org/10.14195/978-989-26-0767-2_1
}

Accessed : $\quad$ 26-Apr-2023 06:28:33

A navegação consulta e descarregamento dos títulos inseridos nas Bibliotecas Digitais UC Digitalis, UC Pombalina e UC Impactum, pressupõem a aceitação plena e sem reservas dos Termos e Condições de Uso destas Bibliotecas Digitais, disponíveis em https://digitalis.uc.pt/pt-pt/termos.

Conforme exposto nos referidos Termos e Condições de Uso, o descarregamento de títulos de acesso restrito requer uma licença válida de autorização devendo o utilizador aceder ao(s) documento(s) a partir de um endereço de IP da instituição detentora da supramencionada licença.

Ao utilizador é apenas permitido o descarregamento para uso pessoal, pelo que o emprego do(s) título(s) descarregado(s) para outro fim, designadamente comercial, carece de autorização do respetivo autor ou editor da obra.

Na medida em que todas as obras da UC Digitalis se encontram protegidas pelo Código do Direito de Autor e Direitos Conexos e demais legislação aplicável, toda a cópia, parcial ou total, deste documento, nos casos em que é legalmente admitida, deverá conter ou fazer-se acompanhar por este aviso.

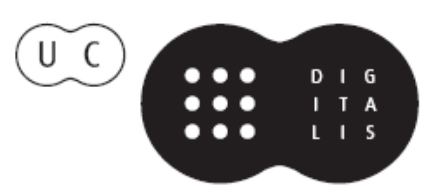




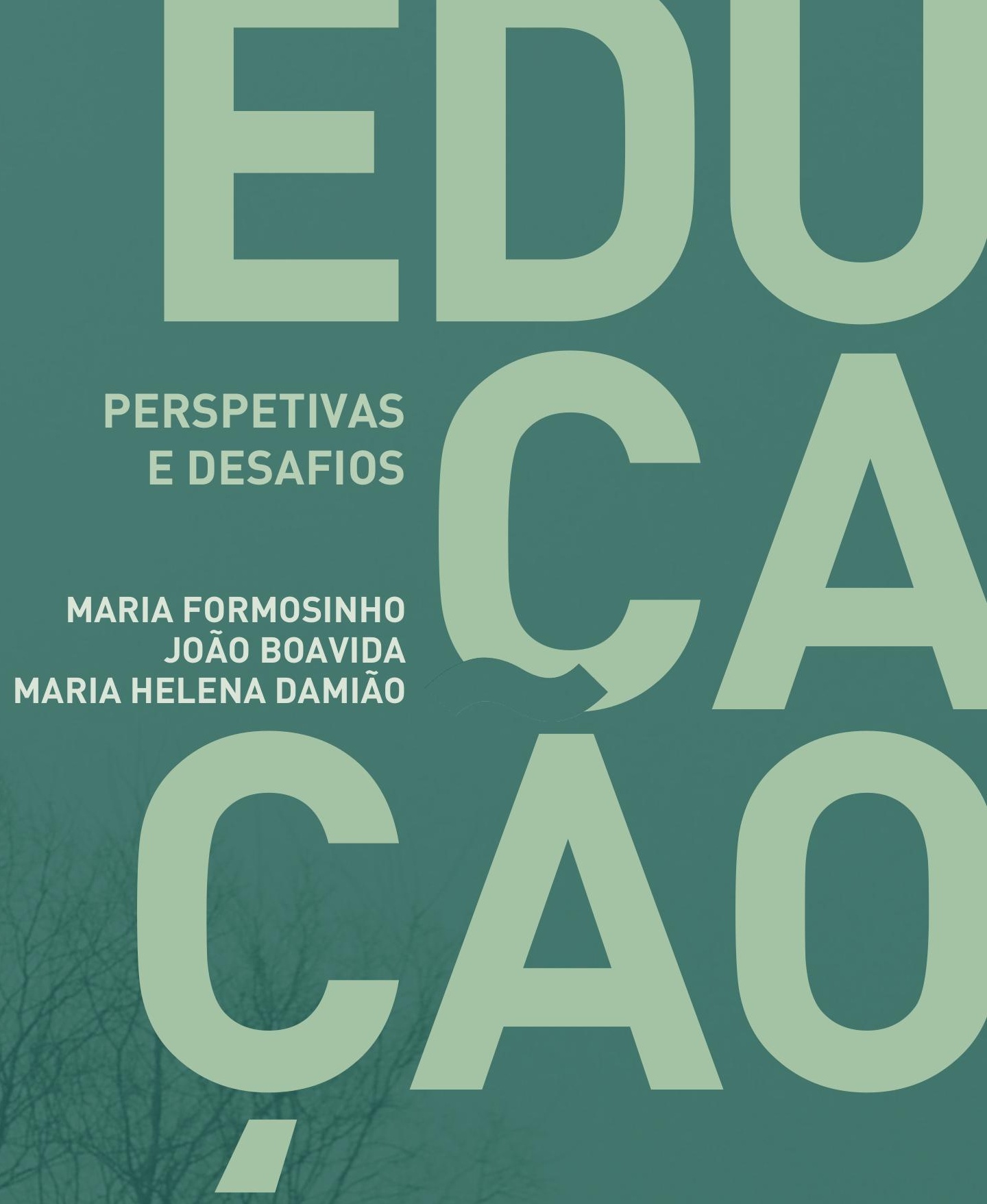

IMPRENSA DA

UNIVERSIDADE

DE COIMBRA

COIMBRA

UNIVERSITY

PRESS 


\author{
João Boavida \\ Universidade de Coimbra
}

\title{
QUE FUNDAMENTOS PARA UMA \\ EDUCAÇÃO EM TEMPO DE CRISE?
}

\section{Introdução}

Destruídas ou, pelo menos, erodidas as estruturas racionais que nos vinham do Iluminismo, somos hoje confrontados com a ausência de ideias de contorno ético suscetíveis de uma aceitação generalizada, e que se apresentem com coerência e força suficientes para criar dinâmicas de valorização moral e social. De facto, vivenciamos as consequências de uma crise moral resultante da conjugação de vários fatores. Um, a já referida destruição ou enfraquecimento das estruturas de racionalidade. A razão, liberta do obscurantismo, fora considerada uma conquista definitiva, e a imperatividade da lei ética, como seu corolário, na linha kantiana, afigurava-se universal e irreversível. Outro fator, e pelas razões de uma importante evolução do espírito científico-positivista, foi a perda do sustentáculo teológico e dos alicerces espirituais que estruturaram durante séculos o pensamento e a ação das grandes massas. Diluíram-se estas duas ordens de influência que, em sentidos opostos e em enquadramentos históricos desencontrados, deram fundamento e orientação aos comportamentos éticos e às dinâmicas intersubjetivas. E, em virtude disso, vemo-nos desprovidos dessas bússolas axiológicas de referência e da orientação que ambas, à sua maneira, proporcionavam.

\section{Do colapso dos fundamentos à refundamentação da ação educativa}

Nestas condições é necessário ir à procura de uma nova ordem de fundamentos para a ação educativa. Esta não pode estar assente em 
meras convenções ou plataformas de entendimento, nem tão pouco remeter-se a uma razão instrumental e técnica que não responde às questões essenciais nem é capaz, pela sua especificidade, de ir além das circunstâncias. Com efeito, pela confluência dos fatores aludidos, tem-se vindo a produzir um esbatimento de contornos axiológicos, juntamente com o sentimento de uma horizontalidade ética de base individual, ao mesmo tempo que se verifica a tendência crescente, no domínio público, para um recuo da moral, para a sobreposição do moral pelo legal e para a redução daquele a este. E, portanto, é crescente a sensação de que se o poder judicial não nos limitar e controlar, isto é, se a pressão sócio-legal não for suficientemente eficaz e dissuasora, nada nos obrigará, no limite, a reconhecer normas para além das que o eu determinar, em cada circunstância, de acordo com o seu interesse ou capricho. O número dos que assim pensam e agem parece ser cada vez maior, as consequências deste individualismo extremo não foram ainda avaliadas em toda a sua extensão, mas são muito preocupantes.

Nestas condições, o problema que se coloca é o seguinte: onde ir encontrar a matriz axiológica consensual que oriente os comportamentos e as ações? Se a racionalização da Idade Moderna, ao desenvolver a autonomia moral, tinha já enfraquecido a componente sociocultural dos comportamentos morais, pela desvalorização da pressão normativa, como é que a filosofia pode reencontrar o ethos dessa necessidade social tão debilitada, sem perder as conquistas individualizantes entretanto obtidas? Como encontrar a base racional e afetiva para qualquer ordem ética, reconhecível e aceite em geral? E que ética desejar, tendo em conta a dispersão das imagens culturais do ser humano, e o derruir de uma razão que se pensava a si própria como universal e nos aparece hoje fragmentada e flutuante?

A este nível a razão fundamentadora tem estado ausente. Mas não pode desistir do seu intento de compreender, de procurar incessantemente o fundamento que a compreensão exige. E embora esta sua vocação esteja dependente da educação, são evidentes as enormes potencialidades da razão que quer fundamentar, desde que facultadas as condições indispensáveis à concretização do seu móbil. 
O que remete o problema à sua raiz. O que é que a educação deve ser a partir do que nós somos? Que exigências a natureza humana postula à educação? Tendo portanto em conta que a educação e a ordem sociocultural em que ancora, face ao individualismo reinante, figuram, para muitos, como dispensáveis ou subordináveis ao eu soberano, como inverter este processo suicidário? E como preservar princípios éticos que estejam para além do individualismo ou das éticas dialógicas, limitadas, em boa medida, pelo circunstancial dos seus participantes? Uma vez que não é previsível um regresso a formas pré-racionalistas de religiosidade que possam repor o esquema teológico da moral e da norma, nem podemos rejeitar todas as suspeições críticas que incidem sobre o projeto da modernidade idealizado pelos humanistas, somos obrigados a repensar a normatividade implícita à ação educativa. Verdade é que a simples análise do processo educativo e das suas formas de avaliação mostram a inevitabilidade das normas. As duas perspetivas da educação - individual e social - são duas faces da mesma moeda, mas o que os períodos críticos nos mostram é o desequilíbrio de uma dessas perspetivas e a necessidade de as reequilibrar. Ora, se os tempos atuais estão pouco sensíveis tanto para uma análise teórica de princípios, como para uma definição de finalidades, poderão eventualmente estar mais sensíveis a um trabalho de análise sobre a educação, enquanto fenómeno humano e cultural que se manifesta em todos os grupos. Deste modo, e porque limitados na procura de princípios fundamentadores, pela falência de uma Razão supostamente universal, e pela ausência de grandes finalidades ou horizontes teleológicos, tanto de natureza escatológica como ideológica, somos compelidos a regressar às origens de um conceito e à análise da sua especificidade.

\section{A educação em busca da sua especificidade}

Os conceitos de educação referem em geral a ação de quem educa e a aceitação por parte de quem é educado, isto é, pressupõem uma educação formal ou formalizante. Mas o que aqui antepomos é de uma conceção de educação enquanto matriz psicoafectiva e sociocultural diluída nas 
situações concretas e constitutiva dos indivíduos e dos grupos. Invocar esta componente material, que está na base da nossa natureza antropológica, parece ser hoje o mais importante, porque de tão desvalorizada se esqueceu, tornando-se quase "invisível”. De facto esta dimensão fundamental corre o risco de se tornar episódica, residual e é, por isso, nas situações informais que a falta de justificação para a ação pedagógica particularmente se denota, em virtude da erosão dos fatores educacionais de natureza psicoafectiva e social, e de uma axiologia individualista transformada em filosofia de vida.

Se não parece haver condições para uma fundamentação tradicional que remeta para uma transcendência, será possível, então, identificar a especificidade do educativo, indo à raiz antropológica que determina o próprio fenómeno. Como refere Formosinho (2009, 171), "a educação atua sobre o sujeito, tal como é, com os seus determinismos biológicos, psicológicos, culturais, mas orienta-se por um normativo axiológico que subentende uma certa conceção antropológica e um certo modelo utópico de sociedade". É por isso um processo muito variado, tanto pelos indivíduos que a assimilam como pelas situações históricas e socioculturais em que se insere e onde acontece. Tem, como refere Delfim Santos (1978, p. 488) as características "da complexidade, da instabilidade e da indefinibilidade que caracterizam o humano", sendo, pois, um meio "ao serviço da transitividade da vida do educando".

Não obstante esta indefinibilidade, a que alude o autor, poderemos falar em algumas características comuns aos fenómenos educativos, embora outro tanto não possamos fazer em relação às situações, pela sua enorme variabilidade. Em primeiro lugar, não há uma educação em abstrato, é sempre um processo pessoal de transformação na base de motivações e de ações diretas e indiretas. Pérez Gómez (1978, p. 153) entende como "educativo todo o influxo exógeno ou endógeno que condiciona, potencia ou inibe o desenvolvimento individual”. É também, sempre, um processo constitutivo; o ser humano é uma "natureza aberta", não programada, e a educação desempenha nele uma tarefa insubstituível, como os casos históricos das "crianças selvagens" o demonstram. Trata-se de um processo contínuo de apropriação de ideias, valores, sensibilidades e condutas 
dependentes de (e criando) estruturas psicoafectivas e racionais, configurando, em cada indivíduo, uma subjetividade no contexto de uma rede intersubjetiva. Ou seja, a educação cria capacidades, dá conhecimentos e ensina comportamentos, gestos e atitudes socialmente aceites, num processo contínuo de transmissão, interiorização e reformulação. Cada ser humano é, nestes termos, produto e produtor de cultura. E, portanto, mesmo quando pareça errático e até contraditório, é um processo com sentido, "ordena-se com vista a alcançar os seus próprios objetivos (...) em redor de um projeto de ação" (Sáenz, 1986, p. 33). Todas as integrações vão sendo feitas, efetivamente, em função do significado que têm para o indivíduo e para os que o cercam. E essas integrações, na medida em que são qualificadoras ou desqualificadoras, incorporam valor ou desvalor.

Reconhece-se, de forma consensual, que as pessoas crescem física e psicologicamente dentro de contextos sociais particulares onde vão ganhando estrutura psicoafectiva e sentido de vida, muitas vezes implícito, conforme a capacidade do próprio, a natureza concreta das situações, a sensibilidade das pessoas envolventes e as estruturas sociais de interpretação e controlo que a sociedade lhes fornece. Por isso se diz que a educação traz a marca do tempo e do lugar. Munõz Rodriguez (2003) chama a atenção para a importância do "território" como variável que orienta o processo educativo, como se fosse o epicentro da construção da identidade das pessoas. Além disso, a educação funciona simultaneamente quer por aspiração e motivação do educando, quer como constrangimento ou pressão exterior, umas vezes mediante ações espontâneas e intuitivas, outras, subordinada a uma planificação de acordo com objetivos, próximos ou remotos. Finalmente, tudo isto pressupõe a educabilidade (Fermoso, 1982), não só como "categoria antropológica", no sentido que lhe atribui (Carvalho, 2001, p.19), mas também como específico do educativo concreto e na medida em que inere a perfectibilidade. Isto é, a educabilidade tem o duplo sentido de inserção no sociocultural e de constituinte do ser humano.

Neste sentido, trata-se de um conceito abstrato que ultrapassa o próprio conceito de educação, uma vez que é constitutivo dele e elemento indispensável à sua compreensão. E assim, o ser humano é um "ser potencial", 
que fica sempre aquém daquilo que podia ser ou fazer, numa espécie de carência essencial. Mas é sempre, simultaneamente, um ser que vai muito para além do mínimo biopsíquico que poderemos já identificar como humano. A perfetibilidade realça a sua sempre possível dinâmica de melhoria, mas, ao mesmo tempo, a defetibilidade faz recear continuamente pela possibilidade de retrocesso. Neste aspeto, a dinâmica inerente ao processo educacional, espartilhado entre múltiplas coordenadas antitéticas, assegura a sua omnipresente complexidade decorrente da eterna luta antinómica que em si mesmo potencia (Quintana Cabanas, 2002).

\section{Educação e educabilidade: a dimensão antropológica e constitutiva do processo educativo}

Desde os primórdios da humanidade, a educação é uma realidade originária e intrinsecamente humana, acontecendo que, como refere Delfim Santos (1973, p. 42), "em todas as formas de civilização que a história regista, por mais rudimentares que elas sejam, o primado, clara ou não claramente expresso, pertence à educação". Por isso podemos falar da educação como necessidade vital e função direcionada, interligada com os fenómenos sociais e culturais, mas sem com eles se confundir a partir de certo momento da evolução. Na base destes pressupostos somos pois confrontados com uma conceção muito mais radical e ampla da educação, em que a mesma se torna a raiz da vida humana, na sua dimensão pessoal e social (Carrasco \& Dujo, 2001).

De facto, como necessidade vital, é a condição da sobrevivência tanto dos indivíduos como da espécie. Os seres vivos conservam-se e renovam-se por um processo interativo em que as capacidades novas surgem à medida que vamos sendo capazes de ultrapassar dificuldades que até aí não conseguíamos. E essa criação por necessidade transforma-se em novas capacidades que se conservam e transmitem numa função vital para a sobrevivência, constituindo assim um fator condicionador e agregador dos elementos do grupo. A educação é a condição da própria dinâmica social, e esta da sobrevivência de qualquer sociedade. E, por este processo 
de criação e conservação, a educação resulta da vida em grupo e é força de coesão e fator de desenvolvimento desse mesmo grupo. É óbvio que esta dimensão social não exclui a componente pessoal, porque, de facto, "cada homem realiza a sua própria e intransferível experiência vital", a qual só funciona porque, sendo "intransferível, necessita de ser articulada com a experiência vital dos outros homens, para que a vida social seja possível" (Delfim Santos, 1973, p. 442).

A vida de cada ser humano é, de facto, um itinerário particular (Boavida, 1998) que se articula com uma infinidade de outros, constituindo uma teia profunda, vasta e insuperável, sendo certo que é este quadro sociocultural e psicoafectivo que nos permite compreender até que ponto, e desde onde, a educação é um fator constitutivo dos indivíduos e das sociedades. Esta ideia torna-se essencial para compreender a necessidade educativa, que as mentalidades atuais nem sempre parecem entender em toda a sua extensão. A tendência em reduzi-la a uma preparação técnica e profissionalizante limita o reconhecimento do direito e do dever de educar (e de ser educado) e limita a compreensão do carácter imperativo - pessoal e social - que efetivamente tem, teve e é indispensável que continue a ter. Atualmente desloca-se a educação, de algum modo, para as margens do constitutivo da personalidade, pelos aspetos secundários, mas dominantes, do poder, do ter, do desejar, do conseguir e do parecer. Esquece-se assim a pessoa enquanto entidade e núcleo de ação e de decisão, o que dificulta o reconhecimento de que estes atributos da pessoa necessitam da interiorização de princípios e de fins, implícitos ou explícitos, sem os quais é a própria noção de pessoa que perde conteúdo e possibilidade.

A partir do momento em que se percebe esta base indispensável para a compreensão daquilo que somos e podemos ser, abre-se outra perspetiva compreensiva e, simultaneamente, outra possibilidade de fundamentação, ambas indispensáveis para o nosso objetivo. Há no educativo uma raiz antropológica e uma natureza sociocultural que são constitutivas da nossa realidade individual e social. Contudo, temos tendência atualmente para não reconhecer nem valorizar devidamente esta natureza intrinsecamente constitutiva. Está de tal modo dentro de nós, e há uma tal coincidência entre o que somos e o que ela é, que acabamos por não a vislumbrar. 
Sobretudo numa época em que diminuiu muito a conceção e a prática da educação como prescrição e norma, e abunda uma prodigiosa produção virtual onde a densidade ontológica do real se esvanece, esvaziando o indivíduo da pessoa que lhe corresponde.

\section{Especificidade e densidade ontológica do educacional}

Podemos entender o específico da educação como o que não se esgota em nenhuma situação educativa particular, mas está presente em todas as que concretizam formas de melhoria ou aperfeiçoamento; como aquilo que ultrapassa o concreto de cada uma e permanece em todas como uma potencialidade que se especificou, ou que se pode vir a especificar (Boavida \& Amado, 2006). É pois uma realidade potencial, mas que só se revela depois de concretizada, sendo esse facto que lhe dá a existência. Isto permite compreender que há um educativo para lá das situações educativas, e perceber que ele tem uma entidade que não se esgota nas situações formais, embora as integre. Mas enquanto nas situações formais se patenteia intencionalmente, o mesmo não acontece nas situações informais e nos itinerários individuais, onde é preciso recetividade à sua possibilidade e ao seu efeito. Se nenhuma situação especifica o educativo, porque este não se identifica completamente com o carácter concreto das situações propositadamente concebidas para serem educativas, transcenderá, de facto, cada uma em particular, caracterizando-se pelo potencial de mais-valia que contém. Na realidade o ato educativo aparece sempre contextualizado, mas o educativo é o que transcende o contexto, embora nela se apoie. Por isso podemos identificar a natureza educacional de uma situação ou atitude, não tanto pelo concreto da situação, mas por tudo o que de potencialmente perfetível podemos extrair dela.

Há, portanto, uma densidade ontológica no educativo, tal como há uma componente antropológica (Boavida \& Amado, 2006). Esta está de tal modo inserida e confundida com a ontogénese, que corremos o risco de não a reconhecer como um seu elemento dinâmico e constante; a outra, é de tal modo confundível com as situações, pela natureza concreta destas, 
e tão invisível nelas, pelo seu caráter abstrato e variável, que dificilmente a reconhecemos na sua importância e especificidade. É certo que nunca se falou tanto de educação como hoje, nem se investigou tanto, nem o poder político lhe reservou tantas verbas, instituições e recursos humanos. Mas tudo isto tem a ver sobretudo com uma educação formal, que é acima de tudo instrução, aquisição de conhecimento e treino de competências, e cujo objetivo é a aplicação prática e a resposta às necessidades sociais e económicas. Todavia, na medida em que cresceu a importância da formação profissional e técnica, foi diminuindo a componente ética e espiritual da educação. A ideia de aperfeiçoamento individual, de interiorização, de ascese, perdeu de tal modo importância, que é de temer um empobrecimento da pessoa e uma diminuição da sua riqueza potencial.

Podemos pois dizer que não é a educação científica, técnica e profissional que está em crise, por muitas falhas que tenha e por grande que seja essa carência em muitas zonas do globo e em determinados estratos sociais. Falamos de educação como processo individual de aperfeiçoamento, como itinerário pessoal que se serve de todas as ocasiões para progredir e tem em cada pessoa um caminho único e uma singularidade própria. A consciência de que não é a instrução e a preparação técnica e profissional que estão em crise, em virtude da sua solicitação crescente e de uma complexidade técnica e económica cada vez maior, mas a outra, essa subtil e pessoal via de aperfeiçoamento, revela-se no facto de tal processo se ter tornando invisível e silencioso, isto é, não ser reconhecido nem referenciado pelas massas.

Mas se há uma especificidade ontológica que se manifesta no ato educativo, seja explícito ou implícito, em que consiste a sua constância? Se uma dada situação só é sentida como educativa por alguns, ou se só funciona em certas condições, ou se pelas consequências que teve passou a educativa, para alguém, o que há que realçar é que há uma especificidade que atravessa múltiplas situações, que tem a ver com a natureza cultural do homem, sem deixar de ser pessoal e é, portanto, mais profunda, constante e vasta do que aquilo que habitualmente entendemos por educação. Há na vida dos indivíduos uma permanência e uma profundidade essencial que a define, mas que se diluiu, que se 
instrumentalizou e que, por isso, temos dificuldade em reconhecer como consubstancial aos indivíduos e às sociedades. Mas que continua como base essencial dos indivíduos e dos grupos. Podemos perguntar, todavia, por quanto tempo ainda? Quem nos garante que a dinâmica de perfeição que a educação implica não depende dessa educação e está imune ao processo de desvalorização em curso? Mas, sendo assim, que base comum poderemos nós ainda estabelecer?

\section{5. À procura de uma base consensual e constante para a educação}

Em nosso entendimento, o especificamente educativo resulta, de facto, de um certo número de pressupostos, condições e intenções. Os pressupostos desempenham na compreensão deste problema uma função insubstituível. Por exemplo: conceitos como obediência, opção, liberdade, ação, sentido, finalidade, responsabilidade, exigência, valor, consciência etc., são conceitos que não se esgotam nas situações educativas, mas que pressupomos sempre que atuamos como agentes educativos. É certo que nem todos estão presentes numa mesma ocasião, mas são pressupostos aqueles que determinam e possibilitam o educativo de uma dada ação. O pressuposto é aquilo que, de algum modo, prepara para a transformação que a educação faculta, ao predispor e facilitar a aceitação de um aperfeiçoamento que se deseja. É como um reflexo retroativo, é o mínimo em que implicitamente pensamos e exigimos quando sentimos ou acuamos educativamente. Assim sendo, o pressuposto é anterior, em termos intencionais, às próprias situações.

Mas não devemos confundir os pressupostos com as condições educativas, embora estas acompanhem aqueles, enquanto fatores indispensáveis para que as possibilidades educacionais se concretizem. As condições educativas são as circunstâncias que tornam educativamente possível uma situação, e permitem compreender como, e porquê, ela pode ser educativa. Deste modo, sendo sempre mais do que a realidade que se pode observar, sendo uma intenção e uma tensão dinâmica orientada para uma melhoria e uma recetividade a novas aprendizagens, poderemos 
considerar como educativa toda a situação em que se manifeste uma intenção de qualificação, uma qualquer tensão capaz de dinamizar um processo de aperfeiçoamento ou recetividade a uma ideia ou modelo.

Note-se que no caso da educação espontânea não há uma intenção explícita, mas não deixa de haver uma influência ou uma intenção implícita nos contextos culturais do indivíduo e que, ao condicionar-lhe as atitudes, o orientam num sentido que a sociedade considera adequado. Feldman (2003) entende mesmo que a intenção do ato educativo é o principal instrumento da atividade, porque não só lhe dá direção como, constituindo parte instrumental, vai-se adequando e modificando. Do lado do educando, por sua vez, é a consciência dos atos e dos efeitos que as torna as situações educativas. A intenção é a força que ativa os pressupostos e as condições que serão educativas, se a intenção puser a funcionar os mecanismos necessários ao aperfeiçoamento. Na verdade, os efeitos da intenção dependem da recetividade individual, e há, portanto, uma atenção que é determinante para integrar as melhorias conseguidas, reorganizando as possibilidades em função de novas finalidades.

A quantidade e a variedade das situações potencialmente educativas são inúmeras e dependem da sensibilidade dos indivíduos, sendo certo que é este núcleo axial que está enfraquecido, pois se entendermos a educação como processo de aperfeiçoamento e como interiorização sentimos que há uma enorme carência. Por outro lado, como já vimos, o ato educativo nunca é abstrato, mas é indispensável reconhecer que, ao compreender a relação educativa na sua forma mais elementar, mesmo que diluída e dispersa, acabamos por encontrar não só a própria relação humana e as suas influências, mas também a transubjetividade e, através dela, "o valor (...) como uma referência transubjetiva" (Formosinho, 2009, p. 174). Se da relação entre duas ou mais pessoas resultar um aperfeiçoamento numa ou em várias, estamos perante uma interação educativa.

A compreensão da especificidade educativa, da sua variabilidade quase infinita e da constante mistura com componentes de outra natureza pode de algum modo esclarecer a nossa problemática inicial. Na atualidade, o educativo enquanto prescrição e norma desvalorizou-se, mas a educação, mesmo que de tal não se tenha consciência, é o ponto de partida de uma 
realidade psicológica, social e cultural que dela deriva e a ela regressa revertendo num ethos pessoal e social que é uma condição semiótica de interpretação da própria ação.

\section{Conclusão}

A educação tem, portanto, um estatuto duplo de ponto de partida e de horizonte último. O que revela na sua latitude, um ser e um devir, uma instabilidade e uma permanência, uma natureza pontual e uma estrutura circular que nos enquadra e envolve. É desta realidade que se tem atualmente pouca consciência reflexiva. De facto, ocorreu um processo de fragmentação moral que retirou à educação a centralidade humana e enfraqueceu a sua componente normativo-prescritiva, com evidentes consequências societais. Este processo foi potenciado por um individualismo que afirma a liberdade individual como um valor quase absoluto, acabando por criar paradoxos (Camps, 1996), que destroem o indivíduo ou o limitam, embora supostamente figurem promovê-lo ou libertá-lo.

Assim, confrontamo-nos hoje, no campo educacional, com duas realidades que têm tendência para se anular. Por um lado, um eterno educativo, constante na sua especificidade, com uma dimensão social e cultural incontornável, e que vem das origens da hominização; por outro, um individualismo crescente, fruto remoto do racionalismo e do iluminismo, e mais recentemente do liberalismo económico e de um criticismo axiológico, que se está a transformar em indiferentismo e puro subjetivismo. Todos estes contributos foram importantes, de distintas maneiras, para a evolução cultural e civilizacional, mas urge reequacioná-los relembrando a dimensão ética inerente ao processo educativo na sua forma mais extensiva e englobante. A educação, na sua dimensão conceptual e prática, enquanto dinâmica e força de transformação individual e social, constitui o lastro mais radical da nossa entidade e a mais preponderante condição do nosso futuro. $\mathrm{E}$ isto é tanto mais evidente quanto é certo que a especificidade educativa radica de forma absoluta no pressuposto de educabilidade configurado pela plasticidade que nos caracteriza na 
nossa dimensão antropológica. Por esta característica, e pela defetibilidade que nos é constitutiva, estamos formatados para o processo educativo e somos fruto desse mesmo processo, na sua dimensão hominizante e humanizante. E se há um educativo que à custa de ser concultural se tornou em consubstancial, é nesta raiz que nos definimos e determinamos. Nesta medida, é necessário chamar a atenção dos agentes educativos para uma dimensão ética que tem de ser recuperada. Porque o especificamente educativo não se define tanto por uma condição particular de que se parte ou que se assegura, mas por uma dinâmica e um sentido de aperfeiçoamento tendencialmente normativo que as sociedades não podem esquecer sob pena de se condenarem.

\section{Bibliografia}

Boavida, J. (1998). Educação: objectivo-subjectivo. Para uma teoria do itinerário educativo. Porto: Porto Editora.

Boavida, J. \& Amado, J. (2006). Ciências da Educação: Epistemologia, identidade e perspectivas. Coimbra: Imprensa da Universidade de Coimbra.

Carrasco, J. G. \& Dujo, A. G. (2001). Teoría de la Educación. Volumen II. Procesos primarios de formación del pensamiento y la acción. Salamanca: Ediciones Universidad.

Carvalho, A. D. (2001). Epistemologia das Ciências da Educação. Porto: Afrontamento.

Camps, V. (1996). Paradoxos do individualismo. Lisboa: Relógio D’Àgua.

Feldman, D. (2003). Curriculum y objectivo: un viejo tema actual. Educativa, Vol. 6, n. ${ }^{\circ}$, pp. 185-199.

Fermoso, A. J. (1982). Teoría de la educación. Barcelona: CEAC.

Formosinho, M. (2009). Educação e valores: os novos desafios. In A. del Dujo, J. Boavida \& V. Bento (2009). Educação: reconfiguração e limite das suas fronteiras (pp. 170-191). Guarda: Instituto de Estudos Ibéricos.

Munõz Rodriguez, J. M. (2003). Pedagogía de los espacios. Bases teóricas para el analisis y reconstrucción de la educatividad de los espacios. Teoría de la educación, n. ${ }^{\circ}$ 15, pp. 291-295.

Pérez-Gomez, A. (1978). Ciencias humanas y ciencias dela educación. In A. Escolano V. Sánchez de Zavala; M. Fernández Pérez; M. A. Quintanilla \& J. García (1978) Epistemología y educación (pp. 152-157). Salamanca: Sigueme.

Quintana Cabanas, J. M. (1983). Pedagogía, Cência de la Educacion y Ciencias de la Educación. In J. Barcala et al. (Ed.) Estúdios sobre Epistemologia y Pedagogia (pp. 75-105). Madrid: Anaya.

Quintana Cabanas, J. M. (2002). Teoria da Educação - concepção antinómica da educação. Porto: Asa.

Sáenz, O. (1986). Concepto de educación. In Óscar Sáenz (Dir.) Pedagogia general (pp. 9-37). Madrid: Anaya.

Santos, D. (1973). Obras completas - II Da filosofia. Do homem. Lisboa: Fundação Calouste Gulbenkian. 